\title{
PREVALENCE AND DIVERSITY OF CANDIDATUS LIBERIBACTER SPECIES IN MAIN CITRUS GROWING AREAS OF MALAKAND IN NORTHWEST PAKISTAN
}

\author{
Rizwan Khan', Saad Hussain Shah ${ }^{2}$, Ijaz Ahmad', Abdur Rafi', Muhammad Fahim ${ }^{3}$ \\ ${ }^{1}$ Department of Plant Pathology, The University of Agriculture Peshawar, KP Pakistan. \\ ${ }^{2}$ Institute of Biotechnology and Genetic Engineering (IBGE), The University of Agriculture Peshawar, KP Pakistan. \\ ${ }^{3}$ Center for Omic Sciences, Islamia College University Peshawar KP Pakistan.
}

\section{ART ICLE IN F O}

\section{Article history}

Received: June 22, 2019

Revised: September 21, 2019

Accepted: December 15, 2019

\section{Keywords}

Huanglongbing (HLB)

Candidatus Liberibacter

asiaticus CLas

Citrus senensis

Genetic variation
A B S T R A C T

\begin{abstract}
Malakand Division in northwest Pakistan is known for delicious sweet orange, locally called Malta (Citrus sinensis). However, both quality and quantity of the citrus produce has seen a decline over the past few decades. Among production constraints, Huanglongbing (HLB) caused by phloem-limited alpha proteobacterium Candidatus Liberibacter asiaticus (CLas) -an endosymbiont of Asian Citrus Psyllid (Diaphorina citri), is of great economic significance. Therefore, we assessed HLB incidence through symptom-based surveys in major citrus growing areas of Khyber Pakhtunkhwa (KP), Northwest Pakistan. The presence or absence of $C$ Las in the collected citrus samples was confirmed by PCR (Polymerase Chain Reaction) using three set of primers (LSS/LAS606, 0I1/0I2C "16S rDNA" and MH353/MH354 "operon "nusG-rplK"). An average disease incidence of 92\% and severity of $34 \%$ were recorded from main production zones in district Swat, KP. Likewise, in district Lower Dir, HLB had disease incidence and severity of $64 \%$ and $24 \%$, respectively. Molecular diagnostics using 16S rDNA-specific primer LSS/LAS606 and OI1/OI2C, yielded characteristic bands of $500 \mathrm{bp}$ and $1160 \mathrm{bp}$, from all five pooled samples from Swat district, while only two samples of Dir tested positive for both primers. Using an alternative primer MH353/MH354 (nusG-rplK) showed positive amplification for four samples from Swat and two samples of Dir with an amplicon of $631 \mathrm{bp}$. To assess the molecular diversity of the CLas, Sanger sequencing was carried out based on16S rDNA gene. Sequence analysis of $16 \mathrm{~S}$ rDNA gene from all samples revealed maximum similarity with $C$. Liberibacter asiaticus. Among studied isolates, SwKjuPk-5 (MH374503) and SwMtaPk-2 (MH374500) isolates appeared to be more divergent and grouped in separate clad as compared to remaining isolates of Swat and Dir.
\end{abstract}

Corresponding Author: Muhammad Fahim

Email: fahim@icp.edu.pk

(C) 2019 EScience Press. All rights reserved.

\section{INTRODUCTION}

Citrus is one of the major horticultural crops of Pakistan in terms of agricultural export. Kinnow or mandarin
(Citrus reticulate) is grown in Punjab (Altaf et al., 2009) while Sweet orange (Citrus sinenesis L.) in Khyber Pakhtunkhwa (KP) (GOP, 2016). In Pakistan, citrus 
production per unit area is much lower $(9.5$ tons/hectare) as compared to developed countries (25 tons/hectare) (GOP, 2016). The lower productivity can be attributed to abiotic and biotic stresses that also play a role in reducing quality of the produce (Iftikhar et al., 2009; Razi et al., 2011). Among biotic stresses, diseases like huanglongbing (HLB) (Chohan et al., 2007), Citrus tristiza virus (Grimaldi and Catara, 1989) and Citrus canker (Catara et al., 1988) are of great economic significance for citrus production in Pakistan.

HLB is distributed worldwide and has become urgently a supreme challenge for citrus researchers and producing communities in recent past. HLB affects not only productivity, but also reduce fruit quality that often ends up premature fruit drop. In citrus, about $30-100 \%$ losses have been reported due to HLB (Aubert, 1992). The poor physiology of HLB affected citrus cultivars often leads to major losses to citrus industry of the world (CevallosCevallos et al., 2012). This disease is also known as yellow shoot disease or citrus greening disease and was first reported by Reinking (1919) in southern part of China (Graca, 1991).

The causal agent of HLB is fastidious phloem restricted gram-negative bacterium Candidatus Liberibacter (family Rhizobiaceae, $\alpha$-subdivision Proteobacteria) that is rigid rod shaped and its size ranges from 340-540 $\times$ $600-1,500 \mathrm{~nm}$ (Su, 1998). The HLB pathogen is further sub-classified into three species; $C$. L. asiaticus, $C$. L. americanus, and C. L. africanus (Da Graça and Korsten, 2004; Zhao, 1981). In nature, the pathogen is transmitted by Asian citrus psyllid (ACP) vectors, Diaphorina citri and Trioza erytreae (Capoor et al., 1967; McClean and Oberholzer, 1965), and also by grafting (Lopes et al., 2009). Typical symptoms of HLB are foliar mottling and asymmetrical halves. Infected fruits have lopsided strong inversion, remain green forever with distorted seeds, taste salty and bitter (McClean, 1970). HLB symptoms sometime can be confused with deficiencies of zinc, iron and magnesium and viral diseases like CTV disease (Jantasorn et al., 2007).

The disease has been new emerging threat to citrus industry of the world in general and that of Pakistan in particular (Batool et al., 2007). The incidence of HLB has been reported from the regions of Punjab, Jammu Kashmir and Rajasthan near Pakistan's border (Ahlawat and Raychaudhuri, 1988). However, greater incidence of HLB (16-90\%) was reported from orchards of KP and Punjab (Akhtar and Ahmad, 1999). It has been estimated that about $65 \%$ orchards are infected with the disease and its vector is present in Pakistan and India (Ghosh et al., 2015).

Persistent latency of the disease, nature of the pathogen, generic expression and influence of temperature on symptoms in an orchard are the factors which contribute to lack of disease management (Bové, 2006; Da Graça and Korsten, 2004; Halbert and Manjunath, 2004). In the absence of management strategies and resistant/tolerant cultivars, different Liberibacter species from Asia (C. L. asiaticus), Africa (C. L. africanus) and America ( $C$. L. americanus) are evolving rapidly in the region. Therefore, we surveyed major citrus growing areas of Swat and Dir Districts to assess the current prevalence of HLB and understand the molecular systematics of the prevalent Liberibacter species.

\section{MATERIALS AND METHODS}

Survey and sampling of HLB: Symptom-based survey was carried out in the major citrus orchards of two districts of KP province including Lower Dir (Khanpur, Timargara, Khal, Rabat and Talash) and Swat (Jambil, Matta, Barikot, Marghozar and Kanju) from October 2016 to January 2017 as shown in Table 1 and figure 1. From each orchard of Citrus senensis, five different trees were selected randomly on X-pattern. From infected trees, showing characteristic symptoms of HLB, twentyfive leaves were collected for subsequent study and were stored at $-20^{\circ} \mathrm{C}$ until further use. Disease incidence was calculated by using the following formula:

Percent Disease Incidence

$$
=\frac{\text { number of diseased plants }}{\text { total number of observed plants }} \times 100
$$

Disease severity index was calculated by using 0-4 rating scale; $0=$ No symptom, 1 = Yellowing/ chlorosis symptoms on leaves (25\%), 2 = Canopy symptoms and lopsided fruits (26-50\%), $3=$ partially declined tree (5175\%), 4 = Sever dieback ( $>75 \%$ ) (Akhtar and Ahmad, 1999). Percent disease severity was determined by using the equation given below:

$$
\text { Percent Disease Severity }=\frac{\sum n}{4 N} \times 100
$$

DNA extraction: DNA was extracted from the midrib of HLB infected citrus leaves by using CTAB-DNA extraction method of Doyle and Doyle (1987) with some modifications. Nano-drop was performed for concentration and purity of DNA using Li et al. (2006) method. Also, to check the concentration and purity of DNA, the samples were run on $1 \%$ agarose gel for 30 minutes. 
Table 1. Prevalence and PCR base detection of Candidatus Liberibacter asiaticus in the citrus growing areas of Malakand in Northwest Pakistan.

\begin{tabular}{|c|c|c|c|c|c|c|c|c|}
\hline \multirow[b]{2}{*}{ ID } & \multicolumn{2}{|c|}{ Specific Origin } & \multirow{2}{*}{$\begin{array}{c}\text { HLB } \\
\text { Symptoms }\end{array}$} & \multicolumn{2}{|c|}{ Disease index } & \multicolumn{3}{|c|}{ Liberibacter Detection (PCR) } \\
\hline & District & Area & & $\begin{array}{c}\text { Severity } \\
(\%)\end{array}$ & $\begin{array}{c}\text { Incidence } \\
(\%)\end{array}$ & $\begin{array}{l}\text { LSS/ LAS606 } \\
\text { (16S rDNA) }\end{array}$ & $\begin{array}{c}\text { OI1/OI2c } \\
\text { (16S rDNA) }\end{array}$ & $\begin{array}{l}\text { nusG-rplK } \\
\text { (Operon) }\end{array}$ \\
\hline 1 & & Jambil & + & 45 & 100 & + & + & + \\
\hline 2 & & Matta & + & 35 & 80 & + & + & + \\
\hline 3 & Swat & Barikot & + & 25 & 80 & + & + & - \\
\hline 4 & & Marghozar & + & 40 & 100 & + & + & + \\
\hline 5 & & Kanju & + & 30 & 100 & + & + & + \\
\hline 6 & & Khanpur & + & 30 & 80 & + & + & + \\
\hline 7 & & Timargara & + & 20 & 80 & - & - & - \\
\hline 8 & Dir & Khal & + & 35 & 80 & + & + & + \\
\hline 9 & & Rabat & + & 20 & 40 & - & - & - \\
\hline 10 & & Talash & + & 15 & 40 & - & - & - \\
\hline
\end{tabular}

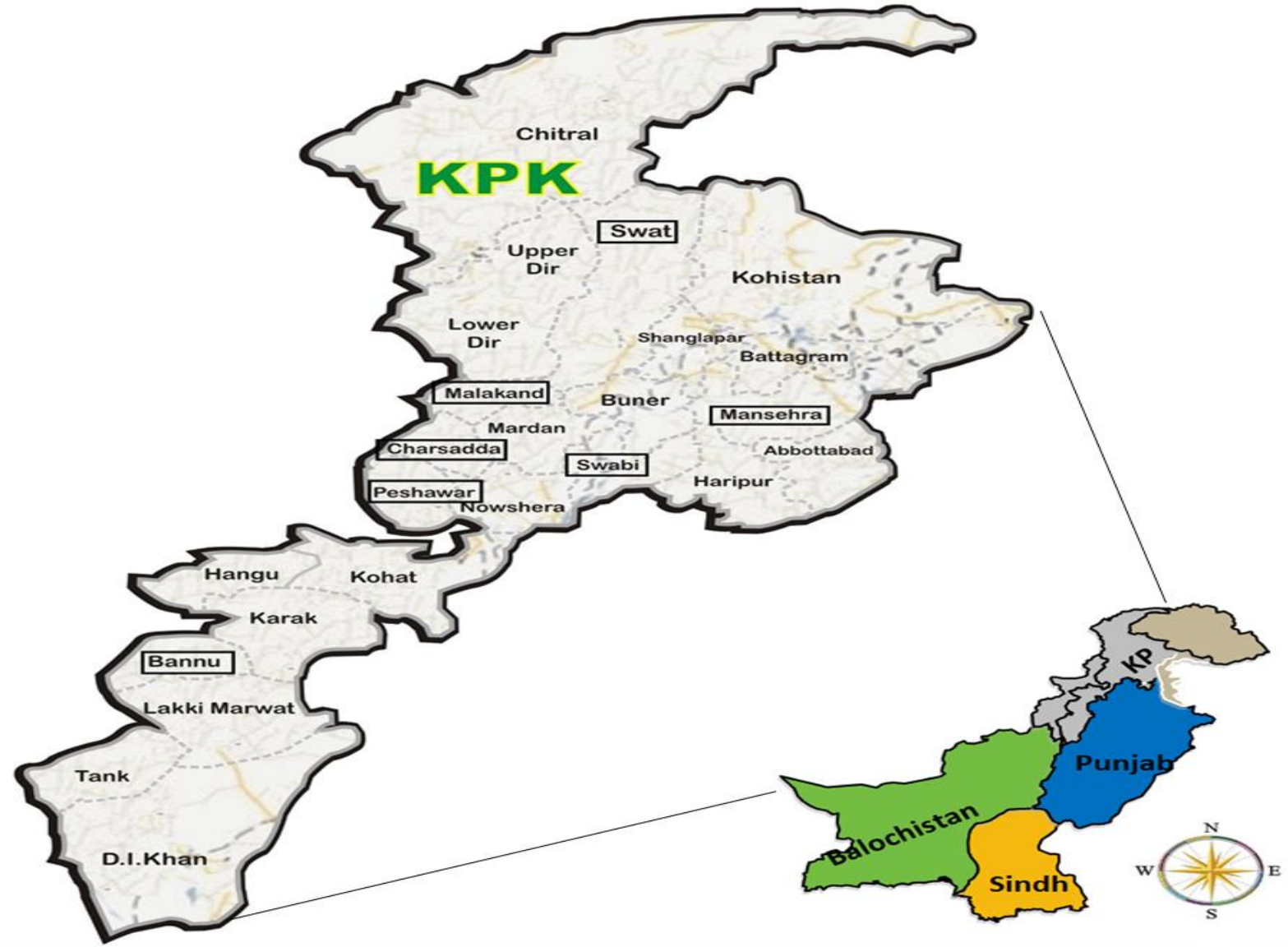

Figure 1. Map of Major Citrus growing areas in Northwest Pakistan affected with Huanglongbing (HLB).

PCR based detection: The selected SSR pairs of primers were used in Polymerase Chain Reaction (PCR) for the region of 16S DNA and operon (Table 2). Amplifications were performed in an automated thermal cycler, a standardized amount of reagents concentrations $(1.5 \mu \mathrm{l}$ of primer for each pair, $7 \mu \mathrm{l}$ of master mix and $0.5 \mu \mathrm{l}$ Platinum Taq-polymerase) were used in PCR for $12.5 \mathrm{ul}$ of reaction. PCR amplification protocol was $96^{\circ} \mathrm{C}$ for 9 min followed by 40 cycles of $96^{\circ} \mathrm{C}$ for $30 \mathrm{sec}$ denaturation. While the annealing temperature of primers; LSS/Las606, OI1/OI2c and MHO353/MHO354, were $53.1,63.8$ and $60.7^{\circ} \mathrm{C}$ respectively for one minute. The initial and final extension was performed at $72^{\circ} \mathrm{C}$ for $30 \mathrm{sec}$ and $7 \mathrm{~min}$ respectively ( $\mathrm{Li}$ et al., 2006). The 
amplified products were visualized on $1.5 \%$ agarose gel, stained with ethidium bromide.

Candidatus Liberibacter sequencing and analysis for genetic diversity: A second round of PCR was carried out for PCR positive samples and the amplified products were sequenced using Sanger Sequencer as recommended by manufacturer (Bio Product). The obtained 16S rDNA sequences were analyzed by BioEdit v7.2 (Hall, 1999). These sequences were compared with sequences retrieved from National Center for Biotechnology Information (NCBI), using Basic Local Alignment Search Tool (BLAST) algorithm (Table 3). The sequences were uploaded to MEGA-7 and aligned using Clustal W (Thompson et al., 2003). Furthermore, the phylogenetic analysis and tree was constructed by neighbor joining method using MEGA-7 software and Randomized Axelerated Maximum Likelihood (RAxML) (Kong et al., 2000).

Table 2. Sets of primers used for detection of HLB in samples collected from district Lower Dir and Swat.

\begin{tabular}{ccccc}
\hline Primer Name & Region & Sequence (5-3) & Reference & Product Size \\
\hline OI1 & 16S rDNA & GCGCGTATGCAAGAGCGGCA & (Jagoueix et al., & $1160 \mathrm{bp}$ \\
OI2c & 16S rDNA & GCCTGCCGACTTCGCAACCCAT & 1997) & \\
LSS & 16S rDNA & ACCCAACATCTAGGTAAAAACC & (Fujikawa and & $500 \mathrm{bp}$ \\
Las606 & 16S rDNA & GGAGAGGTGAGTGGAATTCCGA & Iwanami, 2012) & \\
NUSG-RPLK & nusG-rplK & GTGTCTCTGATGGTCCGTTTGCTTCTTTTA & & \\
(MHO353) & (Operon) & & (Hoy et al., 2001) & $631 \mathrm{bp}$ \\
NUSG-RPLK & nusG-rplK & GAACCTTCCACCATACGCATAGCCCCTTCA & & \\
(MH0354) & (Operon) & & & \\
\hline
\end{tabular}

Table 3. Various retrieved isolates Liberibacter sequences used in the study and the sequences from Swat and Lower Dir region, submitted to NCBI GenBank.

\begin{tabular}{|c|l|l|l|c|}
\hline NO. & Isolates & Isolation source & Origin & Accession No. \\
\hline 1 & Clas A4 & Mandari citrus & China : Guangdong & CP010804 \\
\hline 2 & Clas JXGC & Citrus & China Jiangxi & CP019958 \\
\hline 3 & Clas Gxpsy & Psyllid & China & CP004005 \\
\hline 4 & Clas Psy62 & nd (not determind) & USA & CP001677 \\
\hline 5 & Clas Ishi1 & Nd & Japan & AP014595 \\
\hline 6 & Clso ZC1 & Zebra chip-infected potato & USA: Dalhart, Texas & CP002371 \\
\hline 7 & Claf PTSAPSY & Psyllid & USA & CP004021 \\
\hline 8 & Clam Soa Paulo & Nd & Brazil & EU754742 \\
\hline 9 & Lib Cres BT0 & Babaco pedunkle sap & USA & CP010522 \\
\hline 10 & Lib Cres BT1 & Nd & USA & CP003789 \\
\hline $11^{*}$ & SwJmbPk-1 & Citrus sinensis leaves & Pakistan: KP, Swat & MH374499 \\
\hline $12^{*}$ & SwMtaPk-2 & Citrus sinensis leaves & Pakistan: KP, Swat & MH374500 \\
\hline $13^{*}$ & SwBktPk-3 & Citrus sinensis leaves & Pakistan: KP, Swat & MH374501 \\
\hline $14^{*}$ & SwMzrPk-4 & Citrus sinensis leaves & Pakistan: KP, Swat & MH374502 \\
\hline $15^{*}$ & SwKjuPk-5 & Citrus sinensis leaves & Pakistan: KP, Swat & MH374503 \\
\hline $16^{*}$ & DirKhpPk-6 & Citrus sinensis leaves & Pakistan: KP, Dir & MH374497 \\
\hline $17^{*}$ & DirKhlPk-7 & Citrus sinensis leaves & Pakistan: KP, Dir & MH374498 \\
\hline
\end{tabular}

*This study, nd=not determined

\section{RESULTS}

Disease incidence: The disease incidence of HLB recorded during survey in various orchards is given in figure 2a. Disease incidence was recorded in a range of 40 to $100 \%$. In district Lower Dir, the highest disease incidence was recorded in Khanpur (80\%) and Timargara (80\%). Moreover, the lowest disease incidence was recorded in Talash (40\%). In orchards of Swat, the highest 
incidence was recorded in Jambil (100\%) and Marghozar $(100 \%)$ while the lowest was recorded in Barikot (80\%). The overall mean incidence of $92 \%$ was recorded in Swat and that of $64 \%$ in Lower Dir.

Disease severity: The disease severity in KP ranged from $15-45 \%$ (Figure 2b). In district Swat, the maximum disease severity was recorded in Jambil (45\%) followed by Marghozar (40\%) while the minimum disease severity was recorded in Barikot (25\%). Similarly, in district Lower Dir, the maximum disease severity was recorded in Khal (35\%) followed by Khanpur (25\%) whereas the minimum disease severity was observed in Talash (15\%). The disease severity was higher in district Swat (35\%) as compared to the district Lower Dir (24\%).

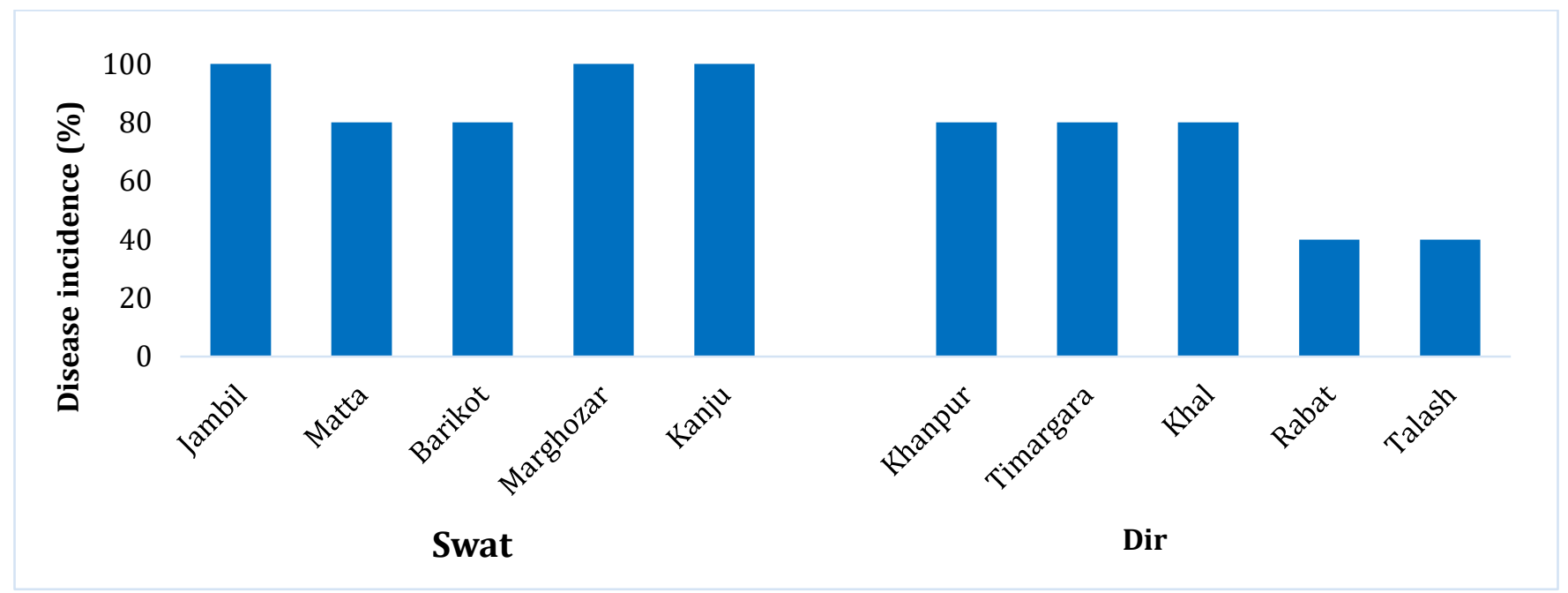

Figure 2a. Disease incidence of HLB in district Lower Dir and Swat of Khyber Pakhtunkhwa, Pakistan.

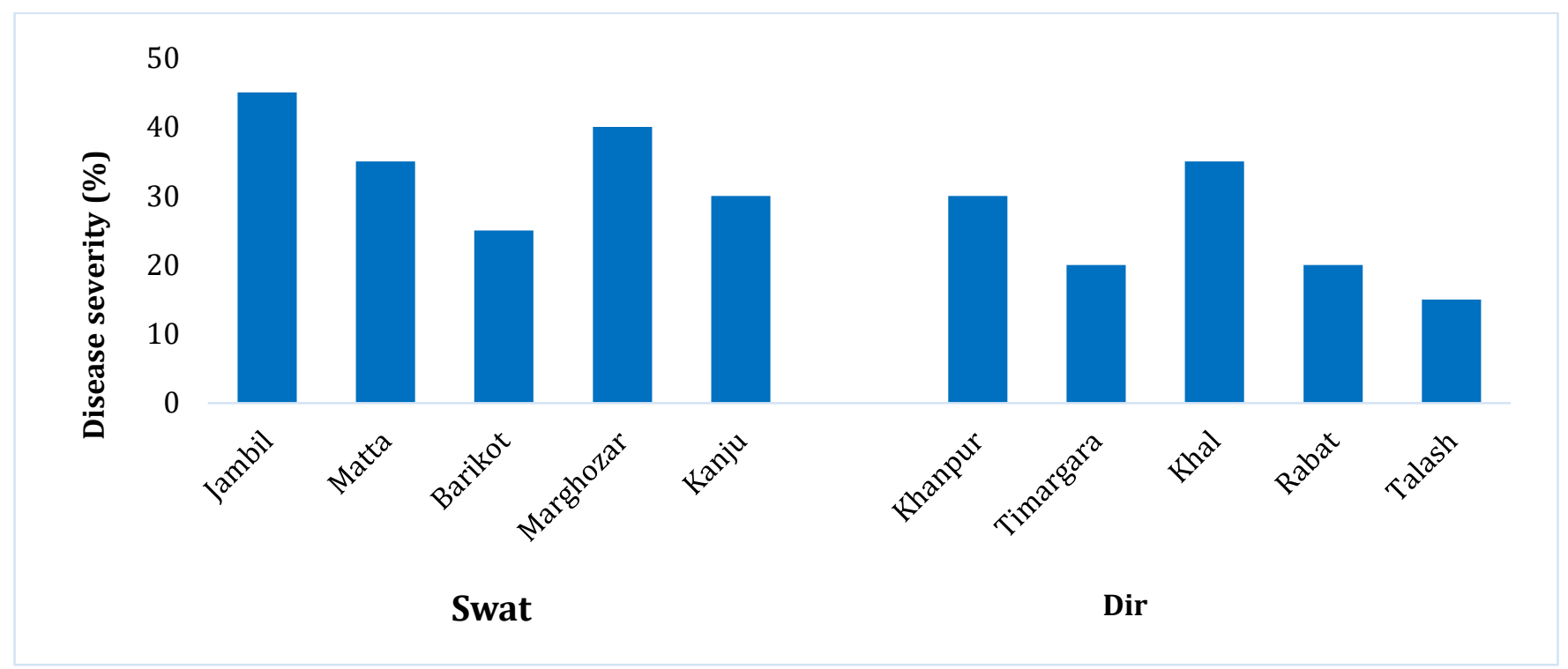

Figure 2b. Disease severity of HLB in district Lower Dir and Swat of Khyber Pakhtunkhwa, Pakistan.

PCR amplified product: Polymerase chain reaction (PCR) used primer LSS/Las606 (16S rDNA), amplified a band of $500 \mathrm{bp}$ for all samples of Swat region; Jambil (S1), Matta (S2), Barikot (S3), Marghozar (S4) and Kanju (S5). Similarly, samples collected from district Lower Dir, the same primer amplified a band of $500 \mathrm{bp}$ for Khanpur (D1) and Khal (D3). However, samples collected from Timargara (D2), Rabat (D4) and Talash (D5) were tested negative for Candidatus Liberibacter species while there was no amplification for negative control (Figure 3a). 
Primer OI1/ OI2c (16r DNA) amplified a band of $1160 \mathrm{bp}$ for the samples of district Swat; Jambil (S1), Matta (S2), Barikot (S3), Marghozar (S4) and Kanju (S5). Similarly, the same primer amplified two samples of Lower Dir; Khanpur (D1) and Khal (D3) whereas, other three symptoms based samples from Timargara (D2), Rabat (D4) and Talash (D5) were found negative in PCR (Figure $3 b$ ).

Primers MH353/ MH354 (631bp) amplified operon (nusGrplK) region of Candidatus Liberibacter spp in the samples of district Lower Dir and Swat. Primer (MH353/ MH354) amplified four samples from district Swat i.e. Jambil (S1), Matta (S2), Marghozar (S4) and Kanju (S5). However, samples from Barikot indicated negative response for the primer. Likewise, in district Lower Dir: Khanpur (D1) and Khal (D3) samples were observed positive for HLB while other three samples from Timargara (D2), Rabat (D4) and Talash (D5), were negative for Candidatus Liberibacter spp. detection (Figure 3c).

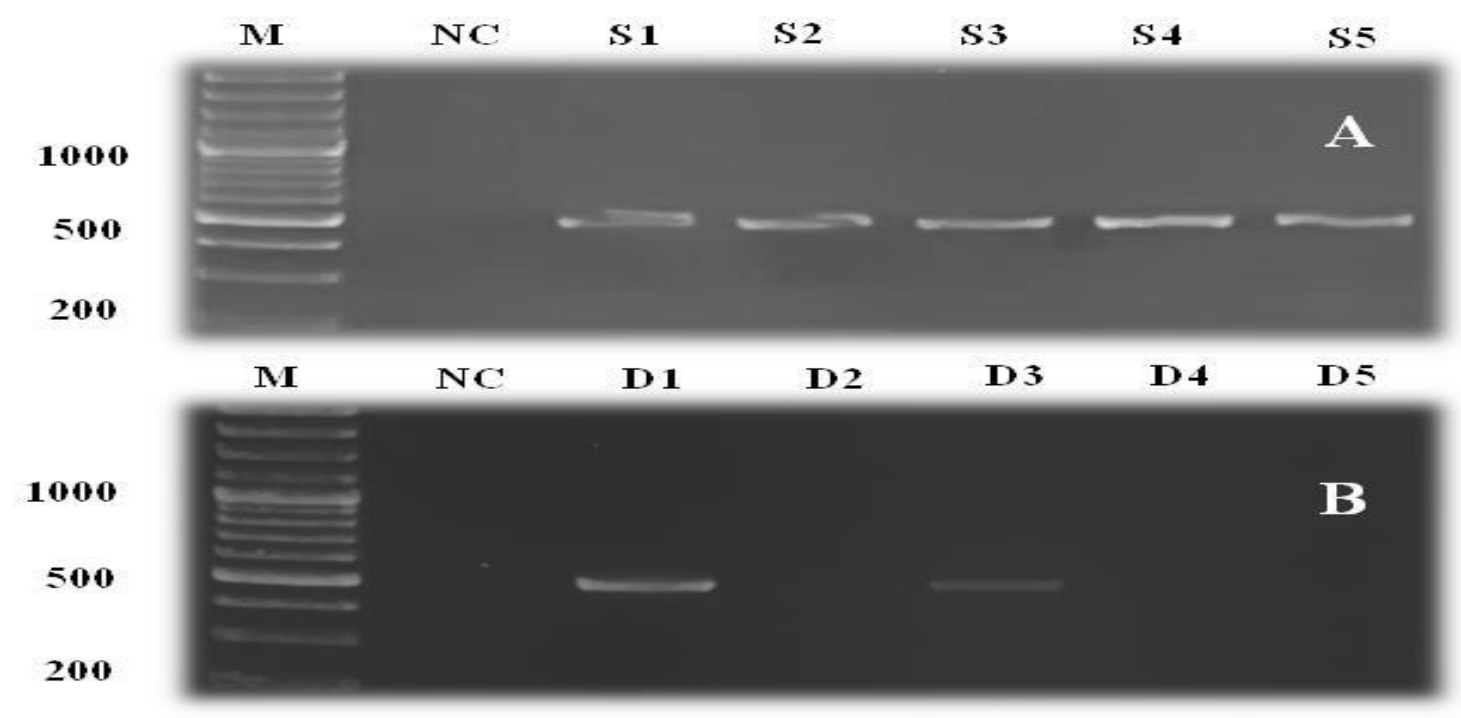

Figure 3a. Amplification of a band of $500 \mathrm{bp}$ for Candidatus Liberibacter asiaticus using primer LSS/LAS606 (16S rDNA) from samples collected from various location of district (A) Swat and (B) Lower Dir. Amplicons were separated on 1.5\% agarose gel. M: 100bp plus DNA ladder, NC: negative control.

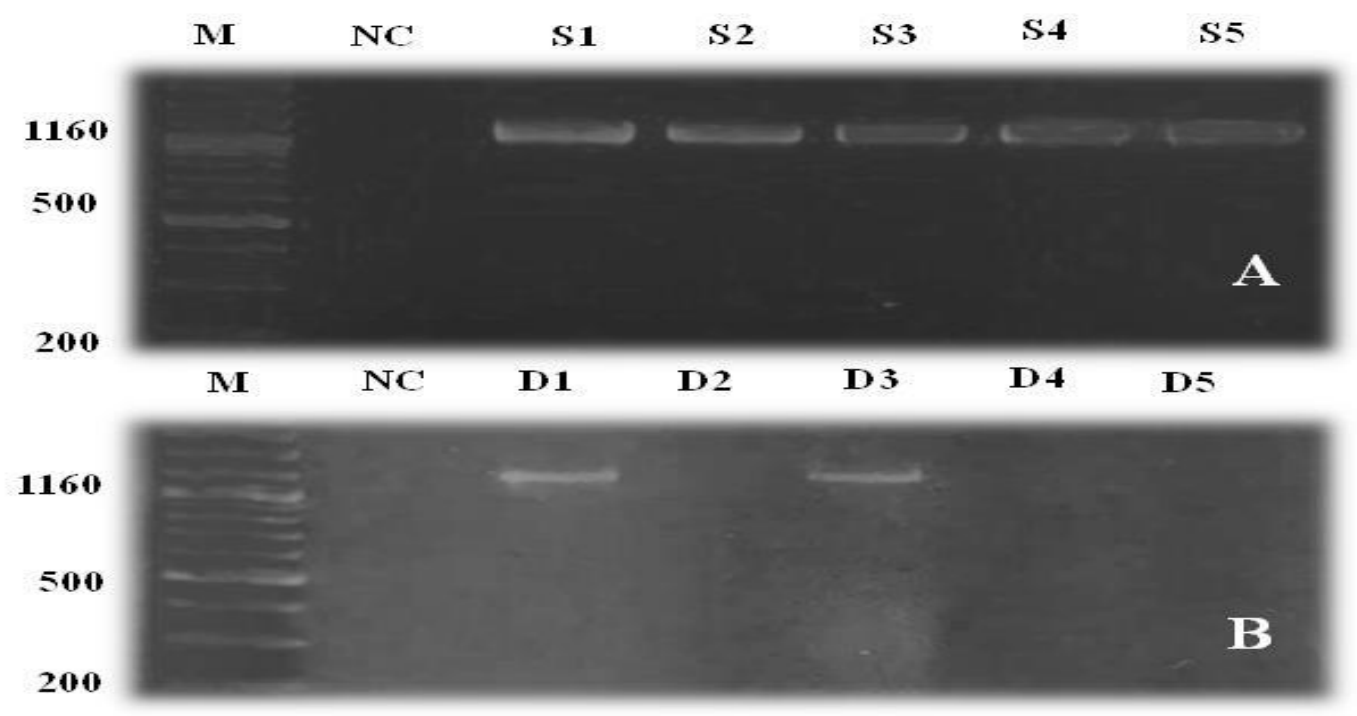

Figure 3b. Amplification of a band $1160 \mathrm{bp}$ forCLas, using primer pair 0I1/ OI2c from samples collected from various location of district (A) Swat and (B) Lower Dir. Amplicons were separated on 1.5\% agarose gel. M: 100 bp plus DNA ladder, NC: negative control. 


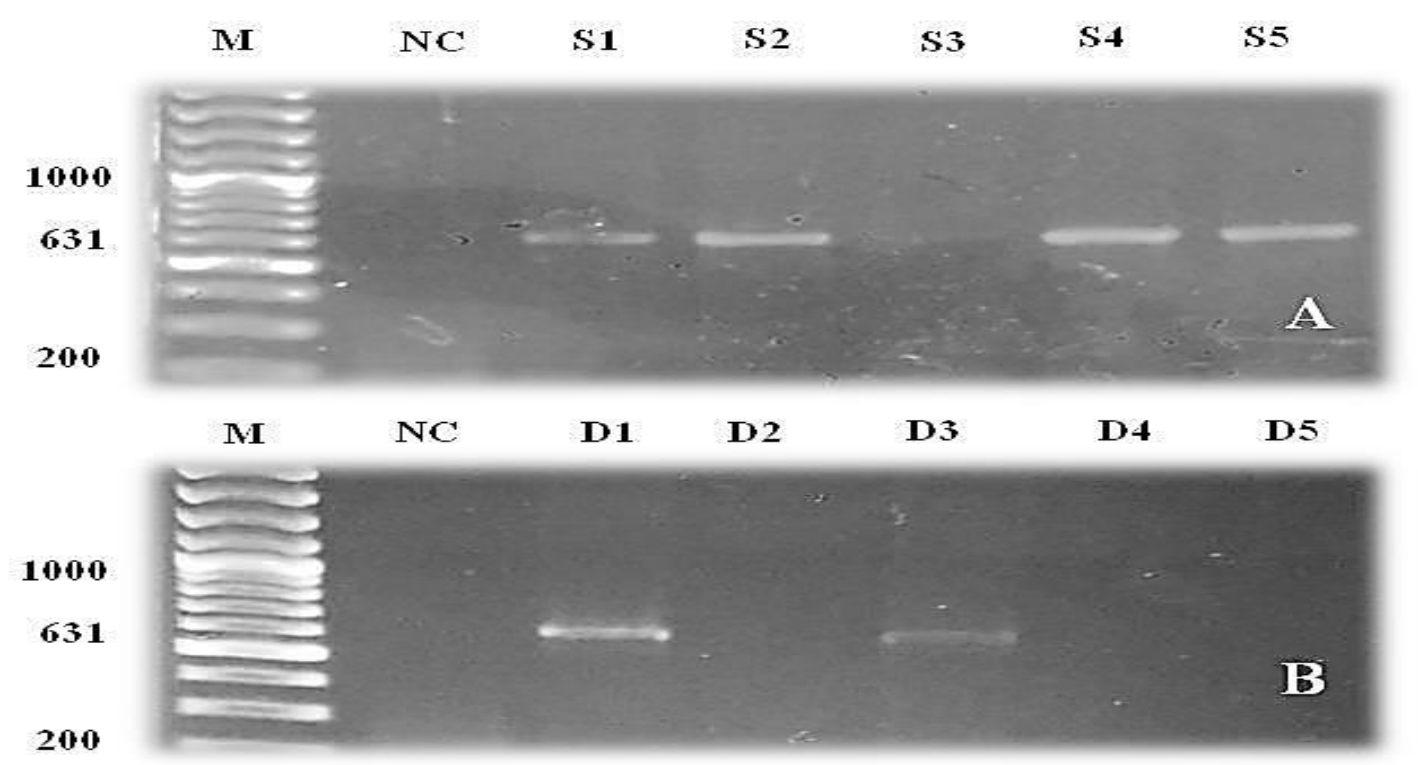

Figure 3c. Amplification of a band of a 631 bp for CLas, using primer pair MH353/ MH354 samples collected from various location of district (A) Swat and (B) Lower Dir. Amplicons were separated on 1.5\% agarose gel, M: 100 bp plus DNA ladder, NC: negative control.

Sequencing of the causal agent of HLB: To further investigate the genetic diversity of Candidatus Liberibacter asiaticus on 16S rDNA gene, PCR positive samples were sequenced and then analyzed. During NCBI BLAST, the obtained sequences from GenBank showed $85-99 \%$ similarity with our sequences (Table 3). In this study, DirKhpPk-6 (MH374497) and DirKhlPk-7 (MH374498) isolates had close similarities with retrieved sequences from GenBank (Accession number CP001677, CP010804 and CP019958) whereas; isolate SwBktPk-3 (MH374501) had resemblance with Clas Gxpsy (CP004005). Likewise, isolates collected from Swat; SwJmbPk-1(MH374499) and SwMzrPk-4 (MH374502) were also similar to CLas Ishi-1 (AP014595). Among Swat and Lower Dir isolates; SwMtaPk-2 (MH374500) and SwKjuPk-5 (MH374503) showed diversity and produced an isolated cluster. The phylogenetic tree indicates that Clam Soa Paulo (EU754742), CLaf PTSAPSY (CP004021), Clso ZC1 (CP002371) and other isolates Lib cres BT0 (CP010522) and Lib cres BT1 (CP003789) formed a separate clade from Liberibacter asiaticus isolates. In precise, multiple sequence alignment and phylogenetic analysis, based on $16 \mathrm{~S}$ rDNA revealed that KP-isolates reported in present study are mostly similar to Candidatus Liberibacter asiaticus having accession numbers (CP010804, CP019958, CP004005, CP001677 and AP014595), compared to others $C$. Liberibacter spp. The homology of isolates; DirKhpPk-6 (MH374497), DirKhlPk-7 (MH374498), SwBktPk-3 (MH374501), SwJmbPk1(MH374499) and SwMzrPk-4 (MH374502) were about 97-99\% with C.Las sequences in NCBI database. However, isolates SwMtaPk-2 (MH374500) and SwKjuPk-5 (MH374503) showed 85-90\% homology with the Liberibacter species retrieved from NCBI database (Figure 4).

\section{DISCUSSION}

Citrus has been one of the major export products of Pakistan (GOP, 2016), however, the citrus orchards in Pakistan are increasingly coming under severe pressure from HLB (Hussain et al., 2019; Khan et al., 2014; Qasim et al., 2018; Razi et al., 2014). Among several biotic stresses, HLB is one of the major contributing factors toward quantitative and qualitative losses of fruit in the region. HLB is one of the diseases that not only reduce fruit yield but also alters fruit quality i.e. bad flavor, reduced sugar content, high acidity, distorted fruit shape etc (Spann and Danyluk, 2010).

The present study was, therefore, designed to assess the prevalence of HLB and diversity of Candidatus Liberibacter asiaticus in the Malakand Division of Northwest Pakistan. The study showed that district Swat has been severely affected by HLB disease. The maximum disease incidence and severity were observed in Swat as 
compared to district Lower Dir of the country. HLB affects all varieties and cultivars of citrus like mandarin, sweet orange, grapefruit and tangelo being the most susceptible while pummel, lime and trifoliate orange are the least susceptible (Knapp et al., 2004). Typical HLB symptoms as described by Ahlawat (1997) were noticed in the orchards. It has been reported that most of the orchards (lemon, grapefruit, orange and mandarin) of Punjab and KP showed HLB symptoms (Catara et al., 1991; Munir et al., 2019). The causal agent could even be detected in the asymptomatic citrus trees (Ghosh et al., 2003). Accordingly, most growers start grafting only asymptomatic trees to eradicate the pathogen. While the asymptomatic trees still have the Clas pathogen which hampers the sanitation and eradication practices. There is a delicate balance among temperature, host and the pathogen which provides favorable condition to HLB. The other main factors that contribute to the disease are large numbers of citrus susceptible varieties and host range in the region (Razi et al., 2014). In Malakand Division, it may be the possible reason that nurseries are the initial source of inoculum, since most of the growing stocks in nursery are usually infected with HLB disease (Akhtar and Ahmad, 1999; Munir et al., 2018).

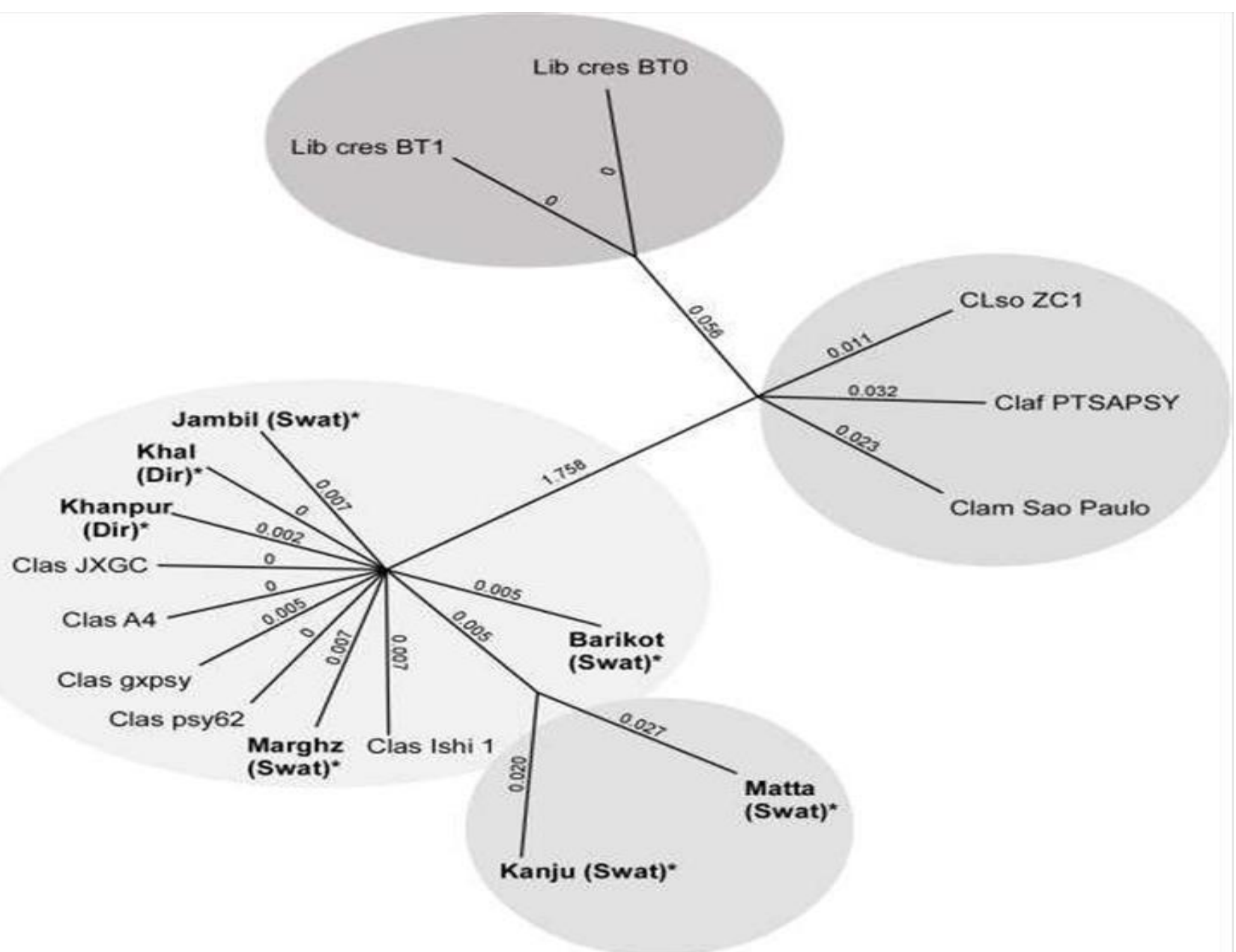

Figure 4. Phylogenetic analysis based on 16S rDNA showing variation for HLB isolates of Swat and Lower Dir of Khyber Pakhtunkhwa-Pakistan. The Bold isolates represent "Liberibacter asiaticus sp" obtained from Swat and Lower Dir, KP, Pakistan.

The disease incidence and severity were very high in Swat. The possible reason behind this alarming situation is the abundant population of vectors in the region which easily multiply the pathogen in their bodies. Other possible reasons may be susceptible varieties and tooold citrus trees in the region which enhanced the possibility of the pathogen's attack and gradual climatic changes in the region are supportive factors. All citrus 
varieties and cultivars were found susceptible to the disease (Chung and Brlansky, 2005). Although some tolerance has been reported in some species of citrus (Rawat et al., 2017) as commercially grown citruses are generally susceptible to the disease. The present findings are similar to those of Akhtar and Ahmad (1999) who found the incidence of HLB between 16-66\% and $90 \%$ in Punjab and KP, respectively. For identification and elucidating molecular diversity, three primers were used for detection of HLB including LSS/LAS606, OI1/OI2C and MH353/MH354, which amplified 16S rDNA and operon (nusG-rplK) region. All samples from district Swat were positive for two pairs of primers (LSS/LAS606 and 0I1/OI2C) and two out of five samples from Lower Dir were amplified by primers (LSS/LAS606 and OI1/OI2C). However, some symptom based collections were PCR negative during the study, that require further investigations if other divergent species are present in the study area (Teixeira et al., 2008). Furthermore, the citrus greening symptoms are sometimes confused with other diseases and nutritional deficiencies (Bové, 2006; Munir et al., 2019). Additionally, an uneven distribution and overlapping of nutrient deficiencies in field causes problem to differentiate the disease, hence molecular tools are useful to distinguish them. The majority of asymptomatic trees may have the pathogen, but the titer of pathogen was not sufficient for detection. Further investigations using new molecular tools such as LAMP PCR, may further shed light on the prevalence and severity of the disease (Choi et al., 2018).

The results of the present study are in agreement with those of Kunta et al. (2014) as it is difficult to distinguish between HLB symptoms and nutrient deficiencies (Munir et al., 2018). MH353/MH354 primer showed less sensitivity for Clas pathogen. It may be due to the presence of inhibitors in the citrus leaf tissues that can affect PCR result (Hocquellet et al., 1999; Li et al., 2006) or the presence of divergent species. Primers LSS/LAS606, OI1/OI2C and MH353/MH354 detected "Candidatus Liberibacter spp." from various samples of citrus. It was observed that CLas is responsible for HLB in citrus (Ruangwong and Akarapisan, 2006; Yaqub et al., 2017) and a pair (OI1/OI2C) of primers was used for the detection of "CLas" (Munir et al., 2019). The primer amplified a product of $1160 \mathrm{bp}$ but no amplicon was detected for healthy samples. Study suggests that
LSS/LAS606 is a robust primer for HLB detection which has high sensitivity at temperature ranges from $50-64^{\circ} \mathrm{C}$. Phylogenetic relationship among various species of Liberibacter was elucidated from other countries on the basis of $16 \mathrm{~S}$ rDNA. In the current study, the species isolated from Swat and Lower Dir isolates were closely related to Candidatus Liberibacter asiaticus (CLas) than other species of Liberibacter (Clam, CLaf and CLso) (Figure 4). Our study is in line with the findigns of Bastianel et al. (2005) and Subandiyah et al. (2000) who differentiated "CLas" from other species of " $C$. Liberibacter" on the basis of 16S rDNA sequences and stated that isolate from Thailand (99.4-100\%), Nepal $(100 \%)$ and India (98.8\%) have closer identity with CLas. These results have similarity with those reported by Ghosh et al. (2003) who confirmed that Indian isolates had $99.9 \%$ similarity with those of China and Thailand. The study also revealed that two isolates of HLB (SwMtaPk-2 and SwKjuPk-5) from Swat region have minor divergence in genetic makeup of "CLas" reported from other countries. A geographical distribution and maximum use of pesticides in the region may be a possible reason for mutation in gene. Lack of quarantine inspection for imported rootstock (HLB infected) also promotes genetic variation.

\section{CONCLUSION}

The prevalence of HLB disease (incidence and severity) was high in district Swat as compared to Lower Dir. Primers used in the study confirmed the presence of HLB (CLas) in the region. Also, LSS/Las606 and 0I1/ OI2c primers were more specific for detection of the pathogen. Phylogenetic relationship indicates that KPPakistan isolates are relatively more similar to $C$. $\mathrm{L}$. asiaticus as compared to $C$. L. africanus and $C$. L. americanus. Pakistan is one of the largest producers of Kinnow with unique taste throughout the world so, it is required to control HLB disease to promote export of the fruit to rest of the world. Molecular tools are requirement of time to identify the infected root stock in nurseries, and quarantine department to prevent propagation of the disease. Detailed analysis of HLB is needed to identify other emerging strains and species. Therefore, this study will be helpful to develop management strategies for HLB.

\section{CONFLICT OF INTEREST}

The authors declare no conflict of interest.

Authors' contribution: All authors equally 
contributed to this paper.

Ethical approval: This article does not contain any studies with human participants or animals performed by any of the authors.

Funding: We received no grant/funding for this study. The study was mainly supported in-kind contribution by all authors.

\section{REFERENCES}

Ahlawat, Y., 1997. Viruses, greening bacterium and viroids associated with citrus (Citrus species) decline in India. Indian Journal of Agricultural Science 67, 51-57.

Ahlawat, Y., Raychaudhuri, S., 1988. Status of citrus tristeza and dieback diseases in India and their detection, Citriculture: Proceedings of the Sixth International Citrus Congress: Middle-East, Tel Aviv, Israel, March 6-11, 1988/scientific editors, R. Goren and K. Mendel, editor, N. Goren. Rehovot, Israel: Balaban

Akhtar, M., Ahmad, I., 1999. Incidence of citrus greening disease in Pakistan. Pakistan Journal of Phytopathology 11, 1-5.

Altaf, N., Khan, A.R., Ali, L., Bhatti, I.A., 2009. In vitro culture of kinnow explants. Pakistan Journal of Botany 41, 597-602.

Aubert, B., 1992. Citrus greening disease, a serious limiting factor for citriculture in Asia and Africa, International Society of Citriculture, p. 820.

Bastianel, C., Garnier-Semancik, M., Renaudin, J., Bové, J., Eveillard, S., 2005. Diversity of "Candidatus Liberibacter asiaticus," based on the omp gene sequence. Applied and Environmental Microbiology 71, 6473-6478.

Batool, A., Iftikhar, Y., Mughal, S.M., Khan, M.M., Jaskani, M.J., Abbas, M., Khan, I.A., 2007. Citrus greening disease-a major cause of citrus decline in the world-a review. Horticulture Science 34, 159-166.

Bové, J.M., 2006. Huanglongbing: A destructive, newlyemerging, century-old disease of citrus. Journal of Plant Pathology, 7-37.

Capoor, S.P., Rao, D.G., Viswanath, S.M., 1967. Diaphorina citri Kuway., a vector of the greening disease of citrus in India. Indian Journal of Agricultural Science 37, 572-576.

Catara, A., Azzaro, A., Davino, M., Grimaldi, V., Hussain, M., Saleem, M., Mirza, M.S., 1991. Survey for Tristeza and Greening in Punjab (Pakistan), International Organization of Citrus Virologists
Conference Proceedings

Catara, A., Azzaro, A., Mughal, S.M., Khan, D.A., 1988. Virus, viroid and prokaryotic diseases of citrus in Pakistan, Proceedings of 6th Conference of the International Organization of Citrus Virologist. Tel Aviv, pp. 957-962.

Cevallos-Cevallos, J.M., Futch, D.B., Shilts, T., Folimonova, S.Y., Reyes-De-Corcuera, J.I., 2012. GC-MS metabolomic differentiation of selected citrus varieties with different sensitivity to citrus huanglongbing. Plant Physiology and Biochemistry 53, 69-76.

Chohan, S.N., Qamar, R., Sadiq, I., Azam, M., Holford, P., Beattie, A., 2007. Molecular evidence for the presence of huanglongbing in Pakistan. Australasian Plant Disease Notes 2, 37-38.

Choi, C.W., Hyun, J.W., Hwang, R.Y., Powell, C.A., 2018. Loop-mediated Isothermal Amplification assay for Detection of Candidatus Liberibacter Asiaticus, a Causal Agent of Citrus Huanglongbing. The Plant Pathology Journal 34, 499-505.

Chung, K., Brlansky, R., 2005. Citrus diseases exotic to Florida: Huanglongbing (citrus greening). Plant Pathology Department Fact Sheet PP-210, Florida Cooperative Extension Service, Institute of Food and Agricultural Sciences, University of Florida. http://edis. ifas. ufl. edu/PP133.

Da Graça, J., Korsten, L., 2004. Citrus huanglongbing: Review, present status and future strategies, Diseases of Fruits and Vegetables. Volume I. Springer, pp. 229-245.

Doyle, J.J., Doyle, J.L., 1987. CTAB DNA extraction in plants. Phytochemical Bulletin 19, 11-15.

Fujikawa, T., Iwanami, T., 2012. Sensitive and robust detection of citrus greening (huanglongbing) bacterium "Candidatus Liberibacter asiaticus" by DNA amplification with new 16S rDNA-specific primers. Molecular and Cellular Probes 26, 194197.

Ghosh, D.K., Bhose, S., Motghare, M., Warghane, A., Mukherjee, K., Ghosh Sr, D.K., Sharma, A.K., Ladaniya, M.S., Gowda, S., 2015. Genetic diversity of the Indian populations of 'Candidatus Liberibacter asiaticus' based on the tandem repeat variability in a genomic locus. Phytopathology 105, 1043-1049.

Ghosh, D.K., Das, A.K., Singh, S., 2003. Individual and mixed infection of Citrus tristeza virus and 
greening Liberobacter in their association with sweet orange decline in the State of Maharasthra. Journal of Mycology and Plant Pathology 33, 6972.

GOP, 2016. Fruit, Vegetables and Condiments Statistics of Pakistan, 2014-15., Government of Pakistan Ministry of National Food Security \& Research Islamabad, pp. 466-469.

Grimaldi, V., Catara, A., 1989. Detection of citrus tristeza and greening in Pakistan through electron microscopy. Journal of Phytopathology 126, 17-21.

Halbert, S.E., Manjunath, K.L., 2004. Asian citrus psyllids (Sternorrhyncha: Psyllidae) and greening disease of citrus: a literature review and assessment of risk in Florida. Florida Entomologist 87, 330-353.

Hall, T.A., 1999. BioEdit: A user-friendly biological sequence alignment editor and analysis program for Windows 95/98/NT, Nucleic Acids Symposium Series. [London]: Information Retrieval Ltd., c1979-c2000., pp. 95-98.

Hoy, M.A., Jeyaprakash, A., Nguyen, R., 2001. Long PCR is a sensitive method for detecting Liberobacter asiaticum in parasitoids undergoing risk assessment in quarantine. Biological Control 22, 278-287.

Hussain, S., Rao, M.J., Anjum, M.A., Ejaz, S., Ali, M.A., Khalid, M.F., Sohail, M., Ercisli, S., Zia-Ul-Haq, M., Ahmad, S., 2019. Effect of different combinations of antibiotics on fruit quality and antioxidant defense system in Huanglongbing infected Kinnow orchards. AMB Express 9, 147.

Iftikhar, Y., Khan, M.A., Rashid, A., Mughal, S.M., Iqbal, Z., Batool, A., Abbas, M., Khan, M.M., Muhammad, S., Jaskani, M.J., 2009. Occurrence and distribution of Citrus Tristeza Closterovirus in the Punjab and NWFP, Pakistan. Pakistan Journal of Botany 41, 373-380.

Jagoueix, S., Bove, J.M., Garnier, M., 1997. Comparison of the $16 \mathrm{~S} / 23 \mathrm{~S}$ ribosomal intergenic regions of "Candidatus Liberobacter asiaticum" and "Candidatus Liberobacter africanum," the two species associated with citrus huanglongbing (greening) disease. International Journal of Systematic and Evolutionary Microbiology 47, 224-227.

Jantasorn, A., Paradornuwat, A., Chowpongpang, S., Chunwongse, J., Thaveechai, N., 2007. Diagnosis of greening disease of Citrus spp. in Thailand, 45.
Kasetsart University Annual Conference, Bangkok (Thailand), 30 Jan-2 Feb 2007.

Khan, A.A., Afzal, M., Qureshi, J.A., Khan, A.M., Raza, A.M., 2014. Botanicals, selective insecticides, and predators to control Diaphorina citri (Hemiptera: Liviidae) in citrus orchards. Insect Science 21, 717-726.

Knapp, J.L., Halbert, S., Lee, R., Hoy, M., Clark, R., Kesinger, M., 2004. The Asian citrus psyllid and citrus greening disease. Agricultural IPM: Fruit (citrus) Florida. IFAS, University of Florida. http.

Kong, W., Deng, X., Liang, Z., Tang, W., 2000. Cloning and sequencing of the citrus Huanglongbing pathogen DNA. Acta Phytopathologica Sinica 30, 71-75.

Kunta, M., Viloria, Z., Hilda, S., Louzada, E.S., 2014. Diverse DNA extraction methods and PCR primers for detection of Huanglongbing-associated bacteria from roots of 'Valencia'sweet orange on sour orange rootstock. Scientia Horticulturae 178, 23-30.

Li, W., Hartung, J.S., Levy, L., 2006. Quantitative real-time PCR for detection and identification of Candidatus Liberibacter species associated with citrus huanglongbing. Journal of Microbiological Methods 66, 104-115.

Lopes, S.A., Bertolini, E., Frare, G.F., Martins, E.C., Wulff, N.A., Teixeira, D.C., Fernandes, N.G., Cambra, M., 2009. Graft transmission efficiencies and multiplication of 'Candidatus Liberibacter americanus' and 'Ca. Liberibacter asiaticus' in citrus plants. Phytopathology 99, 301-306.

McClean, A.P.D., Oberholzer, P.C.J., 1965. Citrus psylla, a vector of the greening disease of sweet orange. South African Journal of Agricultural Science 8, 297-298.

McClean, R.E., 1970. Greening or blotchy-mottle disease of citrus. Phytophylactica 2, 177-194.

Munir, S., Li, Y., He, P., He, P., He, P., Cui, W., Wu, Y., Li, X., He, Y., 2019. Seasonal variation and detection frequency of Candidatus Liberibacter asiaticus in Binchuan, Yunnan province China. Physiological and Molecular Plant Pathology 106, 137-144.

Qasim, M., Baohua, W., Zou, H., Lin, Y., Dash, C.K., Bamisile, B.S., Hussain, M., Zhiwen, Z., Wang, L., 2018. Phylogenetic relationship and genetic diversity of citrus psyllid populations from China and Pakistan and their associated Candidatus bacterium. Molecular Phylogenetics and Evolution 
126, 173-180.

Rawat, N., Kumar, B., Albrecht, U., Du, D., Huang, M., Yu, Q., Zhang, Y., Duan, Y.-P., Bowman, K.D., Gmitter, F.G., 2017. Genome resequencing and transcriptome profiling reveal structural diversity and expression patterns of constitutive disease resistance genes in Huanglongbing-tolerant Poncirus trifoliata and its hybrids. Horticulture Research 4, 17064.

Razi, M.F., Keremane, M.L., Ramadugu, C., Roose, M., Khan, I.A., Lee, R.F., 2014. Detection of citrus huanglongbing-associated 'Candidatus Liberibacter asiaticus' in citrus and Diaphorina citri in Pakistan, seasonal variability, and implications for disease management. Phytopathology 104, 257-268.

Razi, M.F., Khan, I.A., Jaskani, M.J., 2011. Citrus plant nutritional profile in relation to Huanglongbing prevalence in Pakistan. Pakistan Journal of Agricultural Sciences 48, 299-304.

Reinking, O.A., 1919. Diseases of Economic Plants in Southern China. Philippine Agriculturist 8, 109134.

Ruangwong, O., Akarapisan, A., 2006. Detection of Candidatus Liberibacter asiaticus causing citrus huanglongbing disease. Journal of Agricultural Technology 2, 111-120.
Spann, T.M., Danyluk, M.D., 2010. Effects of HLB infection on sweet orange fruit size and quality. Citrus Industry September, 14-16.

$\mathrm{Su}$, H.-J., 1998. Epidemiological review on citrus greening and viral diseases of citrus and banana with special reference to disease-free nursery system. Managing Banana and Citrus Diseases, 13.

Subandiyah, S., Iwanami, T., Tsuyumu, S., Ieki, H., 2000. Comparison of 16S rDNA and 16S/23S intergenic region sequences among citrus greening organisms in Asia. Plant Disease 84, 15-18.

Teixeira, D.C., Eveillard, S., Sirand-Pugnet, P., Wulff, A., Saillard, C., Ayres, A.J., Bové, J., 2008. The tufBsecE-nusG-rplKAJL-rpoB gene cluster of the liberibacters: sequence comparisons, phylogeny and speciation. International Journal of Systematic and Evolutionary Microbiology 58, 1414-1421.

Yaqub, M.S., Khan, I.A., Usman, M., Rana, I.A., 2017. Molecular detection of Candidatus Liberibacter asiaticus, the causal organism of huanglongbing (Citrus greening) in Faisalabad, Pakistan for huanglongbing management. Pakistan Journal of Agricultural Sciences 54, 21-26.

Zhao, X.Y., 1981. Citrus yellow shoot disease (Huanglongbing)-A review, International Society of Citriculture, pp. 466-469. 